\title{
FISIOLOGIA COMPARADA DO FLUIDO ORAL E SUAS PRINCIPAIS APLICAÇÕES CLÍNICAS
}

\author{
Sebastião André Barbosa Júnior \\ Raíssa Ivna Alquete de Arreguy Baptista² \\ Clara Nilce Barbosa ${ }^{3}$
}

BARBOSA JÚNIOR, S. A.; BAPTISTA, R. I. A. de A.; BARBOSA, C. N. Fisiologia comparada do fluído oral e suas principais aplicações clínicas. Arq. Ciênc. Vet. Zool. UNIPAR, Umuarama, v. 18, n. 4, p. 259-268, out./dez. 2015.

\begin{abstract}
RESUMO: O fluido oral é um líquido incolor e viscoso que resulta da combinação entre a saliva e os transudatos da cavidade oral, transudato da mucosa oral e fluido crevicular gengival. A saliva é secretada pelas glândulas salivares, enquanto o transudatos da cavidade oral tem origem nos capilares da mucosa e nos tecidos gengivais. O uso do fluido oral é assegurando por uma ampla base de investigações científicas na medicina humana e veterinária. Vários patógenos podem ser avaliados pela reatividade de anticorpos e ou identificação de antígenos. Além disso, o procedimento de coleta é simples, não invasivo e garante uma amostragem sistemática nos diagnósticos clínicos e em pesquisas. Por conseguinte, as informações relacionadas à secreção e composição, bem como os mecanismos de transporte dos componentes do fluido oral são de grande valor. Objetivou-se com este trabalho realizar uma revisão de literatura sobre o fluido oral, enfatizando o processo de secreção, composição, mecanismos de transporte de substâncias, bem como suas aplicações clínicas e principais limitações nos seres humanos e nos animais domésticos.
\end{abstract}

PALAVRAS-CHAVE: Bem estar. Diagnóstico. Saliva.

\section{COMPARATIVE PHYSIOLOGY OF FLUID ORAL AND MAIN CLINICAL APPLICATIONS}

\begin{abstract}
The oral fluid is a colorless and viscous liquid that results from the combination of saliva and transudates of oral cavity, oral mucosal transudate and gingival crevicular fluid. Saliva is secreted from the salivary glands, while the transudates of oral cavity as its origin in capillary mucosa and gingival tissues. The use of oral fluid is thereby ensuring a broad base of scientific research in human and veterinary medicine. Several pathogens can be assessed by reactivity or identification of antibodies and antigens. Furthermore, the collection procedure is simple, noninvasive and provides a systematic sampling in clinical diagnostics and in research. Therefore, the information related to the secretion and composition as well as the transport mechanisms of the oral fluid components are of great value. The aim of this work is make a critical review of the oral fluid, emphasizing the process of secretion and composition, transport mechanisms of the substances present in the plasma to the oral cavity and its clinical applications and major limitations in humans and domestic animals.
\end{abstract}

KEYWORDS: Diagnostic. Saliva. Welfare.

\section{FISIOLOGÍA COMPARADA DEL FLUIDO ORAL Y SUS PRINCIPALES APLICACIONES CLÍNICAS}

RESUMEN: El fluido oral es un líquido incoloro y viscoso que resulta de la combinación entre la saliva y los trasudados de la cavidad oral, trasudado de la mucosa oral y fluido crevicular gingival. La saliva es secretada por las glándulas salivales, mientras el trasudado de la cavidad oral tiene origen en los capilares de la mucosa y en los tejidos gingivales. El uso del fluido oral es garantizado por una amplia base de investigaciones científicas en la medicina humana y veterinaria. Varios agentes patógenos pueden ser evaluados por la reactividad de anticuerpos y/o la identificación de antígenos. Además, el procedimiento de recogida es simple, no invasivo, y asegura un muestreo sistemático en los diagnósticos clínicos y en la investigación. Por lo tanto, las informaciones relacionadas con la secreción y composición, así como los mecanismos de transporte de los componentes del fluido oral son importantes. El objetivo de este estudio fue realizar una revisión de la literatura sobre el fluido oral, destacando el proceso de secreción, composición, mecanismos de transporte de sustancias, así como sus aplicaciones clínicas y principales limitaciones en los seres humanos y en los animales domésticos.

PALABRAS CLAVE: Bienestar. Diagnóstico. Saliva.

\section{Introdução}

A utilização do Fluido Oral (FO) vem crescendo em diversos contextos, como na fisiologia, imunologia, odontologia, medicina interna, endocrinologia, pediatria, patologia clínica, medicina forense, medicina do esporte, psicologia, psiquiatria e medicina veterinária (PRICKETT; ZIMMERMAN, 2010; BADIYANI; KUMAR; MARU, 2013). Além de um método de natureza não invasiva, seguro, de fácil execução e custo baixo, a utilização do FO como amostra

DOI: https://doi.org/10.25110/arqvet.v18i4.2015.5754

${ }^{1}$ Médico Veterinário e Licenciado em Ciências Agrícolas, especialista em Saúde Pública, mestrando do Programa de Pós-Graduação em Ciência Veterinária (PPGCV) na Universidade Federal Rural de Pernambuco (UFRPE). Endereço para correspondência: Rua Três, nº 95, Bela Vista, Vitória de Santo Antão PE, CEP: 55.608-390. E-mail: sebastiaoandre.jr@hotmail.com.

${ }^{2}$ Médica Veterinária e Licenciada em Ciências Agrícolas, mestre em Ciência Veterinária e doutoranda do Programa de Pós-Graduação em Ciência Veterinária (PPGCV) na Universidade Federal Rural de Pernambuco (UFRPE).

${ }^{3}$ Médica Veterinária, doutora em Ciência Animal, Professora adjunta do Departamento de Medicina Veterinária (DMV) e do Programa de Pós-Graduação em Ciência Veterinária da Universidade Federal Rural de Pernambuco (UFRPE). 
clínica apresenta um baixo risco ocupacional para os profissionais de saúde durante sua coleta e processamento (FERRI, 1998; KAUFMAN; LAMSTER, 2002; AMADO et al., 2006; MOURA et al., 2007; LAMY; MAU, 2012; BADIYANI; KUMAR; MARU, 2013), mostrando ser uma ferramenta que traz praticidade e diminui o estresse provocado pela coleta do sangue, principalmente em animais de produção, favorecendo o bem-estar animal (PRICKETT; ZIMMERMAN, 2010; BARBOSA et al., 2013).

Devido a essas qualidades, observa-se uma crescente utilização do FO em substituição ao sangue como amostra clínica, tanto nos seres humanos, quanto nos animais. Esse cenário demanda conhecimentos específicos sobre o FO, visto que apesar de mais de cem anos do primeiro relato de sua utilização, ainda existem mecanismos fisiológicos e patológicos desconhecidos. A compreensão desses mecanismos tem sido o objetivo de pesquisas científicas, que visam a identificar as características biológicas e moléculas que compõem o FO (KAUFMAN; LAMSTER, 2002; UITTO, 2003; AMADO et al., 2006; MOURA et al., 2007).

É proposto com este trabalho realizar uma revisão de literatura, entre o período de 2000 a 2015, sobre o FO, enfatizando a secreção e composição da saliva e dos Transudatos da Cavidade Oral (TCO), mecanismos de transporte de moléculas do sangue para o FO, bem como as suas principais aplicações clínicas e limitações nos seres humanos e nos animais domésticos.

\section{Desenvolvimento}

Para a realização desta revisão de literatura foram realizadas buscas nas seguintes bases de dados: SciELO, LILACS (Biblioteca Virtual de Saúde - BVS), Portal de Periódicos CAPES, PubMed e Google Acadêmico. Como descritores foram utilizados os termos: Fluido Oral, Saliva Total, Transudato da Cavidade Oral, Fluido Crevicular, Transudato da Mucosa Oral, Fisiologia do Fluido Oral e Fisiologia da Saliva. Foi designado o corte temporal de quinze anos, entre os anos de 2000 a 2015, utilizando-se quando não encontrado no período definido, estudos de outros anos pertinentes ao desenvolvimento desta revisão. Também foram utilizados livros, dissertações, teses e demais artigos científicos de referência no assunto cujo ano de publicação extrapolou o corte temporal definido.

\section{Conceitos básicos}

\section{Saliva}

É comum denominar de saliva todo o líquido presente na cavidade oral, no entanto, a saliva vem a ser especificamente o fluido originado pelas glândulas salivares (HODINKA; NAGASHUNMUGAM; MALAMUD, 1998; CROUCH, 2005). A saliva é secretada pelas glândulas salivares maiores ou principais: parótida, submandibular e sublingual, e pelas glândulas menores ou acessórias localizadas difusamente na cavidade oral (GEORGE; FITCHEN, 1997; HUMPHREY; WILLIAMSON, 2001; McKIE; ANDREW; MAPLE, 2002; DELIMA; VAN DYKE, 2003; PRICKETT; ZIMMERMAN, 2010; BADIYANI; KUMAR; MARU, 2013). A saliva é obtida diretamente nos ductos salivares, no caso das glândulas maiores por meio de coletores especiais, e filtro de papel e micropipetas quando nas menores (HODINKA; NAGASHUNMUGAM; MALAMUD, 1998).

\section{Transudatos da cavidade oral}

Os TCO são fluidos que têm origem nos capilares da mucosa oral e na base dos sulcos localizados entre a gengiva e os dentes, sendo nomeado respectivamente de Transudato da Mucosa Oral (TMO) e de Fluido Crevicular Gengival (FCG) (GEORGE; FITCHEN, 1997; HODINKA; NAGASHUNMUGAM; MALAMUD, 1998; BARROS et al., 1999; DELIMA; VAN DYKE, 2003; PRICKETT; ZIMMERMAN, 2010). Segundo Hodinka, Nagashunmugam e Malamud (1998) os termos "fluido crevicular" e "fluido crevicular gengival" também podem ser utilizados para descrever o TMO.

\section{Fluido Oral}

O FO é o termo utilizado para nomear o líquido incolor e viscoso presente na cavidade oral dos seres humanos e outros animais, podendo ainda ser denominado de "Saliva Total" ou "Saliva Mista". Trata-se de uma mistura complexa, que contem outros fluidos além da saliva, provenientes do transudato do soro sanguíneo de capilares presentes na cavidade oral e de secreções oro-nasais (GEORGE; FITCHEN, 1997; KAUFMAN; LAMSTER, 2002; MCKIE et al., 2002; DELIMA; VAN DYKE, 2003; CROUCH, 2005).

\section{Secreção}

\section{Saliva}

A saliva é uma secreção exócrina mucoserosa, límpida, ligeiramente ácida, produzida por glândulas salivares. Os termos maiores e menores referem-se ao tamanho anatômico das glândulas salivares (EDGAR, 1992; HUMPHREY; WILLIAMSON, 2001), porém, Navazesh (1993) classifica as glândulas salivares maiores como principais. As glândulas salivares maiores ou principais incluem os pares de glândulas parótidas encontrados adjacente ao maxilar e ao ramo da mandíbula, enquanto as glândulas submandibulares e sublinguais estão localizadas na parte inferior da cavidade oral. As glândulas menores estão distribuídas no lábio inferior, língua, palato, bochechas e faringe (NAVAZESH, 1993).

Nos mamíferos as glândulas salivares variam em estrutura, localização, tamanho, número e composição (SHACKLEFORD; WILBORN, 1968). Nos seres humanos e nos animais domésticos, como o cão, o gato, os ruminantes, os equinos e os suínos, há pelo menos três grandes glândulas salivares principais, com algumas diferenças entre as espécies, e outras glândulas numerosas, porém menores, consideradas acessórias (SHACKLEFORD; WILBORN, 1968; HERDT, 2004; ARGENZIO, 2006). Com relação às glândulas principais, os humanos possuem a parótida, a submandibular e a sublingual (NAVAZESH, 1993), os equinos e suínos tem a parótida, a mandibular e a sublingual (SISSON, 1986a, b; DYCE; SACK; WENSING, 1997), os ruminantes possuem quatro, a parótida, a mandibular e a sublingual, que é dividida em duas partes, uma monostomática e outra polistomática 
(HABEL, 1986; DYCE; SACK; WENSING, 1997) e o cachorro e o gato tem a parótida, mandibular, sublingual e zigomática (ELLENPORT, 1986; DYCE; SACK; WENSING, 1997; WIGGS; LOBPRISE, 1997).

Cada uma dessas glândulas principais drena para um ducto principal que possui uma abertura única para a cavidade oral. As glândulas acessórias estão localizadas nas superfícies dos lábios, palato, bochecha e faringe. Essas estão ligadas à cavidade oral por numerosos ductos de excreção situados nas bochechas e na língua (HUMPHREY; WILLIAMSON, 2001; HERDT, 2004; ARGENZIO, 2006; GUYTON; HALL, 2006; JUNQUEIRA; CARNEIRO, 2012).

As glândulas salivares contêm dois tipos de células de secreção nos ácinos, as serosas e as mucosas. As células serosas, com características de produção de proteínas, secretam um conteúdo seroso, rico em enzimas, importante no processo digestivo de moléculas. Enquanto, as células mucosas, produzem uma secreção mucosa, rica em glicoproteínas, com evidência para a mucina, sendo responsável pela lubrificação e proteção dos tecidos da cavidade oral (GUYTON; HALL, 2006; JUNQUEIRA; CARNEIRO, 2012).

A secreção da saliva é um processo que ocorre em duas etapas: a primeira envolve a secreção da saliva pelos ácinos, e a segunda, esta ligada a troca de íons que acontece posteriormente nos ductos salivares (GUYTON; HALL, 2006). Os ácinos produzem uma saliva primária rica em água, eletrólitos, enzimas e muco, que ao fluir por meio dos ductos sofre modificações na sua composição iônica (ARGENZIO, 2006; GUYTON; HALL, 2006; SJAASTAD; SAND; HOVE, 2010; EDGAR et al., 2014).

Quando a saliva primária chega aos ductos salivares, os íons de sódio são absorvidos e os íons de potássio são secretados, num processo de troca. Entretanto, a absorção de sódio excede a secreção de potássio, deixando o fluido com uma negatividade elétrica, esta característica faz com que os íons de cloreto sejam absorvidos de forma passiva e íons bicarbonato sejam secretados de forma ativa nos ductos salivares (APS; MARTENS, 2005; ARGENZIO, 2006; GUYTON; HALL, 2006). Esse processo faz com o que a saliva contenha quantidades elevadas dos íons potássio e bicarbonato, e quantidades baixas dos íons sódio e cloreto, em sua forma final (GUYTON; HALL, 2006).

O grau da alteração das secreções acinares nos ductos coletores depende da velocidade de produção da saliva. Quando há alta taxa de fluxo salivar ocorre pouca modificação, que resulta em alta tonicidade e concentração de eletrólitos, em comparação às baixas taxas de fluxo (HERDT, 2004; SJAASTAD; SAND; HOVE, 2010; EDGAR et al., 2014).

$\mathrm{O}$ equilíbrio entre as atividades das fibras nervosas parassimpáticas e simpáticas determinam o volume e a composição da saliva (SJAASTAD; SAND; HOVE, 2010). As glândulas salivares recebem suprimentos simpáticos e parassimpáticos, tendo o último uma maior importância no processo (DYCE; SACK; WENSING, 1997).

As células secretoras dos ácinos das glândulas salivares são estimuladas principalmente pelos sinais dos nervos parassimpáticos que se originam nos núcleos salivatórios. Esses se localizam no tronco encefálico, aproximadamente na junção da medula e da ponte, sendo excitados por estímulos gustativos e táteis da língua e de outras áreas da boca e fa- ringe (DYC; SACK; WENSING, 1997; GUYTON; HALL, 2006).

A salivação também sofre estímulos do Sistema Nervoso Central (SNC) quando, por exemplo, existe uma expectativa de comer e por consequência ocorre um grande estímulo de salivação (HERDT, 2004; GUYTON; HALL, 2006). Pavlov em seu experimento demonstrou que a estimulação parassimpática foi provocada em cães pelo som de uma campainha. Os cães foram treinados para receber o alimento após o som de uma campainha. Esse estudo foi uma das primeiras demonstrações da influência do SNC sobre as funções digestivas (HERDT, 2004).

A salivação ocorre ainda em resposta a reflexos que se originam no estômago ou no intestino delgado, especialmente quando se trata de irritações ou enjôos. A saliva, quando engolida, pode remover o fator irritativo ou neutralizar uma substância (GUYTON; HALL, 2006).

As células secretoras salivares também contêm receptores adrenérgicos que são ativados por estímulos simpáticos que contribuem pouco com a salivação (HERDT, 2004; GUYTON; HALL, 2006). Os nervos simpáticos se originam nos gânglios cervicais superiores e penetram nas glândulas salivares por meio das superfícies das paredes dos vasos sanguíneos (GUYTON; HALL, 2006).

Outro fator que também afeta a produção salivar é o suprimento de sangue ofertado para as glândulas salivares. A estimulação parassimpática induz um aumento na salivação e também uma vasodilatação dos vasos que irrigam as glândulas (GUYTON; HALL, 2006). Por outro lado, a ação simpática promove uma vasoconstrição, que retarda a velocidade do fluxo salivar, alterando sua composição (DYCE; SACK; WENSING, 1997).

\section{Transudatos da Cavidade Oral}

A cavidade oral é revestida por uma membrana úmida que forma uma barreira estrutural entre o corpo e o meio externo, chamada de mucosa oral (BELLO, 2009; FELLER et al., 2013). Essa mucosa é constituída por dois tipos de tecido, o epitelial e o conjuntivo, sendo conectados por meio da membrana basal. Essa membrana possui várias funções, ajuda na fixação entre os tecidos, filtra moléculas e serve também de guia de migração celular em processo de reepitelização (SQUIER; KREMER, 2001; BELLO, 2009).

A gengiva é uma membrana mucosa que está aderida ao periósteo dos ossos mandibular e maxilar (JUNQUEIRA; CARNEIRO, 2012). Do ponto de vista morfológico e funcional o epitélio gengival constitui-se em três partes distintas: o epitélio oral ou externo, o epitélio sulcular e o epitélio juncional. A função do epitélio gengival é proteger as estruturas mais profundas e permitir trocas seletivas com o ambiente local (SILVEIRA, 2008).

O epitélio sulcular é responsável pelo revestimento do sulco gengival e pode agir como uma membrana semipermeável, que origina o fluido crevicular genvival (FCG) que é exsudado para o sulco (SILVEIRA, 2008). Esse se localiza circundando a coroa dentária, entre o esmalte e o epitélio acima do epitélio juncional (JUNQUEIRA; CARNEIRO, 2012). O sistema circulatório responsável por manter e nutrir o tecido gengival é composto de circulação sanguínea e linfática (SILVEIRA, 2008). 
A rota de transudação dos TCO são semelhantes, o transudato é formado nos capilares sanguíneos e linfáticos presentes no tecido conjuntivo abaixo da mucosa oral e tecido gengival gerando um fluido intersticial que se acumulará na região, passando posteriormente pelos espaços intracelulares relativamente amplos do epitélio, transudando na mucosa oral e no sulco gengival, formando o TMO e o FCG, respectivamente (FERRI, 1998; BARROS et al., 1999; DELIMA; VAN DYKE, 2003; FIORELLINI; KIM; ISHIKAWA, 2007; PRICKETT; ZIMMERMAN, 2010)

Fiorellini, Kim e Ishikawa (2007) relataram que o sulco gengival contém um fluido que exsuda do seu interior, proveniente do tecido conjuntivo gengival que passa através do fino epitélio sulcular e que possui a capacidade de expulsar partículas estranhas e bactérias do seu interior. Os mesmos autores acreditaram que o fluido possa lavar o sulco de substâncias, contendo proteínas plasmáticas que podem melhorar a adesividade do epitélio ao dente, possuir propriedades antimicrobianas e iniciar a atividade dos anticorpos na defesa da gengiva.

\section{Composição}

\section{Saliva}

O principal componente da saliva é a água que corresponde a mais de $90 \%$, além de componentes orgânicos e inorgânicos. O primeiro corresponde à complexidade de proteínas, e o segundo, principalmente ao sódio, potássio, cloro e bicarbonato. $\mathrm{O}$ cálcio, magnésio e fosfato estão presentes, porém em concentrações menores (APS; MARTENS, 2005; CHIAPPIN et al, 2007; LAMI; MAU, 2012). As principais funções atribuídas à saliva são umedecer e lubrificar a mucosa oral e os alimentos iniciando o processo da digestão, bem como a higiene e proteção da cavidade oral (KAUFMAN; LAMSTER, 2002; HERDT, 2004; ARGENZIO, 2006; JUNQUEIRA; CARNEIRO, 2012). Uma função salivar deficiente propicia o aparecimento de doenças na cavidade oral (HERDT, 2004).

A saliva contém enzimas que são fundamentais para a diversas funções, como as lipases, proteinases, mucinas, DNase e RNase (APS; MARTENS, 2005; LAMY; MAU, 2012). Em animais onívoros, como o rato, suíno e seres humanos, a saliva contém uma enzima que é responsável pela digestão do amido, a amilase salivar (HERDT, 2004; ARGENZIO, 2006). Também apresenta uma função de agente tamponante, ajudando na manutenção de um $\mathrm{pH}$ neutro na cavidade oral das espécies (JUNQUEIRA; CARNEIRO, 2012).

Tratando-se de proteção, a secreção salivar desempenha uma função importante contra bactérias, fungos e vírus através da ação de enzimas, como a lisozima, lactoferrina, lactoperoxidases, cistatinas, histatinas, que atuam diretamente nos microorganismos ou se ligando as moléculas necessárias para a manutenção desses (APS; MARTENS, 2005; LAMY; MAU, 2012). A saliva também tem um mecanismo de resposta imune específica, representada pela Imunoglobulina A (IgA), sendo produzida por plasmócitos presentes nas glândulas salivares (NAIR; SCHHROEDER, 1986; TIZARD, 1998). A secreção salivar ainda protege os dentes por meio da formação de uma película, devido o fato das proteínas salivares serem ricas em uma substância chamada prolina, que se ligam ao cálcio (JUNQUEIRA; CARNEIRO, 2012).

Em algumas espécies, tais como, felinos e caninos, a saliva tem um importante papel na regulação da temperatura corpórea, mediante o resfriamento evaporativo (HERDT, 2004; ARGENZIO, 2006; JUNQUEIRA; CARNEIRO, 2012). De acordo com Argenzio (2006) este processo é tão eficaz quanto a evaporação do suor nos humanos.

Os hormônios também podem ser encontrados na saliva, por exemplo, o cortisol, que devido a sua solubilidade em lipídios pode ser facilmente detectado, independente do fluxo salivar. A sua taxa de difusão é elevada, o que mantém uma relação constante entre os níveis salivares e séricos. O aumento do cortisol sérico reflete na concentração do cortisol salivar em menos de cinco minutos (VINNING et al., 1983; KAUFMAN; LAMSTER, 2002; CASTRO; MOREIRA, 2003).

\section{Transudatos da Cavidade Oral}

O TCO é uma complexa mistura de substâncias que apresenta uma composição similar ao soro sanguíneo, como proteínas e imunoglobulinas, além de microorganismos bucais, células estruturais do periodonto e mucosa oral, que são moléculas provenientes da cavidade oral (UITTO, 2003).

As imunoglobulinas $\mathrm{G}(\mathrm{IgG})$ e $\mathrm{M}(\mathrm{IgM})$, presentes no plasma, são transferidas de forma passiva para o TCO. A quantidade de anticorpos específicos encontradas nesse assemelham-se ao do plasma sanguíneo (MACRE, 2008).

Os TCO tem um importante papel na saúde bucal, atuando como barreira imunológica e antibacteriana, por meio do transporte de anticorpos para o interior do sulco gengival e mucosa oral, atuam na limpeza mecânica baseada na força exercida pela transudação do fluido no sulco e na mucosa, além de auxiliar na adesão do epitélio da gengiva ao dente (GOODSON, 2003; GRIFFITHS, 2003; UITTO, 2003 ; SILVEIRA, 2008).

Além desse papel preventivo, os TCO, no caso o FCG, tem um grande potencial para servir como indicador do estado biológico do periodonto (FIORELLINI; KIM; ISHIKAWA, 2007; UITTO, 2003). Embery e Waddington (1994) afirmam que o fluido possui uma variedade de substâncias que servem como potenciais marcadores de atividade de doença periodontal e podem ser divididos em grupos: grupo da placa microbiana (endotoxinas, enzimas e produtos finais de metabolismo); grupo da perda celular (enzimas dos leucócitos, lactoferrinas e lisozimas); grupo da perda tecidual (colágeno, proteoglicanos e matriz proteica) e fatores de perda relacionado à resposta imune (imunoglobulinas, complemento e citocinas).

No sulco gengival saudável, a quantidade de fluido é pequena, já durante o processo inflamatório, essa quantidade aumenta consideravelmente (FIORELLINI; KIM; ISHIKAWA, 2007). Silva, Sallum e Nogueira Filho (2004) relataram que o fluido é gerado por um estímulo químico ou mecânico sobre o tecido gengival que desencadeia uma reação inflamatória, promovendo um aumento da permeabilidade e consequente saída de líquidos dos vasos. De acordo com os autores o fluido é composto por substâncias derivadas do soro, leucócitos, bactérias, células epiteliais descamadas, cé- 
lulas de tecido conjuntivo além de macromoléculas diversas derivadas dos tecidos gengivais e ósseos; refletindo processo de saúde e doença no periodonto.

\section{Mecanismos de transporte}

O transporte de substâncias é o caminho para que as moléculas do soro possam constituir o FO, seja por meio da saliva ou do TCO. O transporte nas glândulas salivares é realizado por duas rotas, a transcelular e a paracelular. A rota intracelular mais comum é a difusão passiva, embora o transporte ativo também seja bastante requisitado. Por via extracelular, o mecanismo mais comum é a ultrafiltração que ocorre entre as junções estreitas das células. As moléculas do soro também compõem o FO como resultado do mecanismo de transudação (KAUFMAN; LAMSTER, 2002; PFAFFE et al., 2011).

As investigações que demonstraram uma ligação do FO na troca de substâncias com a circulação sistêmica iniciaram a partir da segunda metade do século passado. Prickett e Zimmermam (2010) chamam a atenção para a relação existente entre a circulação sistêmica e o FO, levantada nos trabalhos de Brill e Krase (1958) ao utilizar uma injeção intravenosa de um corante fluorescente em cães, de Maddonia, Bahn e Calandra (1966) que demonstraram a passagem do vírus Coxsackie B-1 da circulação sistêmica para o FO em coelhos e o de Challacombe et al (1978) trabalhando com anticorpos.

\section{Transporte Passiva}

O transporte passivo é a rota mais comum para as substâncias do sangue migrarem para o FO. Os capilares em torno das glândulas salivares são permeáveis para muitas moléculas pequenas. Para que uma molécula sérica atinja a saliva por difusão, é necessário atravessar cinco barreiras: a parede capilar, o espaço intersticial, a membrana da célula basal do ácino ou do ducto celular; o citoplasma do ácino ou do ducto celular e a membrana da célula luminal (HAECKEL; HANECKE, 1996; PFAFFE et al., 2011).

O movimento efetivo de moléculas na difusão passiva ocorre do local de maior gradiente eletroquímico para o de menor gradiente eletroquímico. Quanto maior o gradiente de concentração, maior será a taxa de movimento por meio da membrana. Neste tipo de migração não é necessário nenhum transportador específico e nenhuma energia, apenas o gradiente de concentração (MOYES; SCHULTE, 2010)

A capacidade de difusão passiva de uma molécula depende principalmente de seu tamanho e da sua carga elétrica. Moléculas polares (com desequilíbrios elétricos) e com peso molecular maior de 100D tem dificuldades de atravessar membranas celulares. As membranas das células ductais são compostas por fosfolipídios. Se uma molécula é naturalmente grande e polar, terá uma passagem mais difícil e demorada, devido as suas características estruturais e elétricas. Porém, algumas moléculas polares, relativamente pequenas, como a água, conseguem atravessar a dupla camada fosfolipídica, assim como também moléculas maiores solúveis em solventes oleosos, como os hormônios esteroides (HEIDEMANN, 2004; PFAFFE et al., 2011).

Os hormônios esteroides são ácidos graxos que por serem lipofílicos e relativamente pequenos em tamanho passam facilmente por difusão passiva, não sendo influenciado pelo fluxo salivar. Enquanto as moléculas ligadas às extensas cadeias de proteína, como a albumina sérica, são grandes para entrar por essa rota (PFAFFE et al., 2011).

Os capilares presentes abaixo da mucosa oral, bem como entre os dentes e a gengiva são responsáveis pela condução do transudato da mucosa oral. Esse transudato é rico em imunoglobulinas como a IgA secretora, IgM e IgG, que são transportados de forma passiva para a cavidade oral (HODINKA; NAGASHUNMUGAM; MALAMUD, 1998).

\section{Transporte ativo}

O transporte ativo é uma segunda via para a entrada de moléculas na saliva. As células utilizam este meio de transporte para movimentar moléculas por meio da membrana contra os gradientes eletroquímicos (GUYTON; HALL, 2006; MOYES; SCHULTE, 2010; PFAFFE et al., 2011).

Essa é a rota utilizada pela $\operatorname{IgA}$ secretora (sIgA). A IgA polimérica, que é secretada pelas células do linfócito $\mathrm{B}$, quando próximas às células das glândulas salivares, se liga aos receptores de $\operatorname{IgA}$ presentes nas células do ácino. Logo após, a IgA é internalizada, transportada por transcitose e liberada na saliva. Na mucosa oral, a sIgA tem grande importância imunológica, pois impede a aderência e penetração de microorganismos (PFAFFE et al., 2011).

\section{Ultrafiltração}

A ultrafiltração é um mecanismo paracelular que ocorre nos espaços entre as células dos ácinos e ductos. Para esse tipo de transporte é necessário que as moléculas sejam relativamente pequenas que consigam atravessar as bicamadas fosfolipídicas das membranas celulares, devido também as suas cargas elétricas. A ultrafiltração também pode acontecer entre as Junções Gap as células que secretam uma única substância. Apenas moléculas com peso molecular inferiores a 1900 Dáltons, como a água, catecolaminas e esteroides, são transferidas mediante o mecanismo de ultrafiltração. As concentrações dessas substâncias na saliva são 300 a 3.000 vezes menores do que no plasma sanguíneo (PFAFFE et al., 2011).

\section{Transudação}

Outra rota de transporte de moléculas do sangue para o FO é a transudação, na qual os componentes do soro localizados nos capilares do interior da cavidade oral, na mucosa e entre os dentes e gengivas, chegam ao FO pelos transudatos da mucosa oral e sulco gengival. A presença de moléculas típicas do plasma no FO depende deste mecanismo de transporte (HODINKA; NAGASHUNMUGAM; MALAMUD, 1998; KAUFMAN; LAMSTER, 2002; PFAFFE et al., 2011).

De acordo com Griffiths (2003), Uitto (2003) e Silveira (2008) a presença de TCO já era notada desde o século XIX, mas foi em meados do século XX que pesquisadores começaram a entender a natureza e importância dos TCO. Brill e Krase (1958) foram os primeiros a demonstrar o processo que eles denominaram de "Transudação Passiva". Os pesquisadores aplicaram injeções de um corante fluorescen- 
te, fluoresceína sódica, na musculatura posterior da coxa de seis cães e avaliaram o tempo de transudação do corante em diferentes mucosas. Após três minutos da aplicação do corante, houve transudação na gengiva e mucosa oral, que foram também os primeiros locais de transudação. Segundo os autores, mesmo passados 60 minutos da aplicação do produto, este ainda não tinha transudado em outras mucosas, como palato duro, língua, olhos, cavidade nasal, reto e vagina.

Ainda no século XX, na década de 60, Ratcliff (1966), injetou carbono coloidal por via intravenosa em ratos Holtzman e constatou que os fluidos intersticiais transportaram as partículas da substância para o sulco gengival. O resultado indicou que a substância foi transportada da corrente sanguínea para o fluido do sulco gengival, corroborando com os encontrados por Brill e Krase (1958).

Uma evidência importante sobre troca de substâncias entre a circulação sanguínea e o FO foi pesquisada por Challacombe et al. (1978), na qual os autores investigaram a passagem de anticorpos do soro para a cavidade oral. Foram aplicadas injeções intravenosas de imunoglobulinas ( $\mathrm{IgG}$, $\operatorname{IgM}$ e IgA) em macacos rhesus. Os anticorpos foram detectados depois de 30 minutos da aplicação no FCG. Este estudo demonstrou a transferência de anticorpos da circulação sistêmica para o FO pelo mecanismo da transudação na cavidade oral.

\section{Aplicação clínica do fluido oral}

A utilização do FO para o diagnóstico de doenças em seres humanos e outros animais tem uma longa história (PRICKETT; ZIMMERMAM, 2010). Um dos primeiros registros científicos envolvendo o $\mathrm{FO}$ em seres humanos foi realizado no ano de 1880 por Sternberg ao descobrir a presença do Diplococcus pneumoniae em sua própria saliva (SHAFIQ; MALHOTRA, 2012). As primeiras publicações sobre o FO na Medicina Veterinária foram feitas por Roux e Nocard em 1890 ao avaliarem de forma indireta o período de eliminação do vírus rábico na saliva de cães experimentalmente infectados.

O uso do fluido oral como amostra clínica tem sido desenvolvido em várias espécies animais. De acordo com Kaufman e Lamster (2002) a utilização do FO é assegurado por uma ampla base de investigações científicas. Kaufman e Lamster (2002) e Moura et al. (2007) argumentam que o FO vem auxiliando no diagnóstico de patologias sistêmicas, como nos casos de doenças infecciosas, autoimunes, hereditárias e neoplasias malignas. Também tem sido utilizado em casos de doenças localizadas na cavidade oral, em pesquisas ligadas a mensuração de drogas ilícitas e hormônios, na psiquiatria e em estudos voltados a medicina forense.

Estudos apontam que o FO é amplamente utilizado no diagnóstico laboratorial de diversos patógenos de grande importância para a saúde humana, como o vírus da hepatite A, B e C (AMADO et al., 2006), do sarampo (HELFAND et al., 1996), do HIV (FERRI, 1998; HODINKA; NAGASHUNMUGAM; MALAMUD, 1998), da Doença de Chagas (BARROS et al., 1999) e da caxumba (WARRENER; SAMUEL, 2006), que podem ser avaliados pela reatividade de anticorpos, bem como pela a identificação de antígenos ou ácidos nucleicos.

Também é possível identificar proteínas indicado- ras de doenças degenerativas como o câncer da boca, mama e pâncreas, analisando somente os metabólitos presentes no fluido oral humano (GEORGE; FITCHEN, 1997; KAUFMAN; LAMSTER, 2002; MOURA et al.. 2007; SUGIMOTO et al., 2010). Ngounou Wetie et al. (2015) recentemente realizaram um estudo piloto cujo objetivo foi identificar biomarcadores salivares da Desordem de Espectro Autista (ASD) em humanos. $\mathrm{O}$ estudo encontrou diferença significativa entre as proteínas salivares de indivíduos do grupo controle e do grupo com a ASD.

Os primeiros estudos sobre a detecção do cortisol no FO ocorreram na década de 60. Esses estudos foram realizados com diversos objetivos, entre eles, a detecção dos hormônios esteroides relacionados com a Síndrome de Cushing (KATZ; SHANNON, 1964). As substâncias ilícitas, tais como as anfetaminas, os opioides e a cocaína também podem ser detectadas no FO, cuja presença é testada nos atletas (SANTOS et al., 2007). Na medicina Legal e Forense o FO tem sido utilizado como amostra clínica de eleição para fornecimento de DNA de suspeitos em investigações de paternidade e cenas de crimes (PANDESHWAR; DAS, 2014).

$\mathrm{Na}$ Medicina Veterinária Prickett e Zimmerman (2010) relatam que os estudos realizados objetivam principalmente com a investigação de patógenos e anticorpos associados às doenças infecciosas, já se trabalhando com diversas espécies, tais como felinos, caninos, equinos, ovinos, bovinos e suínos. Lami e Mau (2012) destacam que além dos anticorpos e antígenos das doenças, a proteômica do FO, pode ser utilizada como ferramenta voltada ao estado fisiológico e a aspectos da nutrição, servindo principalmente ao monitoramento de animais de produção.

As recentes publicações envolvendo o FO destacam os animais de produção, principalmente a espécie suína que tem gerado amplas perspectivas no desenvolvimento de métodos laboratoriais, bem como a sua aplicação nos diagnósticos laboratoriais, nos monitoramentos de rebanhos e avaliação do bem-estar animal (PRICKETT; ZIMMERMAN, 2010; BAPTISTA, 2012). Na América do Norte, já é possível identificar essa tendência, onde o número de testes imunoenzimáticos e moleculares à base do FO aumentou de 10.329 para 52.000 (KITTAWORNRAT et al., 2013).

Além dos patógenos e anticorpos, também é possível detectar no FO dos suínos hormônios e proteínas indicadores do bem-estar animal. A dosagem do hormônio cortisol é utilizada para monitorar o estresse, assim como as Proteínas de Fase Aguda (PFA), que além do estresse, indicam processos inflamatórios e infecciosos no animal (GUTIERREZ et al., 2009; BAPTISTA; BERTANI; BARBOSA, 2011).

Na metade do século XX surgiram os primeiros estudos sobre a composição de proteínas na saliva dos suínos: presença de amilase em suínos jovens (HUDMAN et al., 1957), detecção das PFA (GUTIERREZ et al., 2009; BAPTISTA; BERTANI; BARBOSA, 2011) e Amiloide Sérica (SOLER; GUTIÉRREZ; CÉRON, 2012).

$\mathrm{Na}$ espécie suína, os primeiros estudos sobre o cortisol no FO surgiram na década de 1980. Os trabalhos abordavam a correlação entre o cortisol salivar e o sérico, bem como a mensuração do estresse em diferentes situações, tais como o transporte, mistura dos animais e privação de água e alimento (PARROTT; MISSON; BALDWIN 1989; PARROTT; MISSON, 1989). 


\section{Limites da utilização do fluido oral}

As concentrações dos componentes no FO variam de acordo com a espécie, o indivíduo e o momento em que é realizada a coleta de amostra (BOACKLE; SUDDICK, 1984; EDGAR, 1992; TENOVUO; LAGERLO, 1995; LLENA-PUY, 2006). A diferença entre os indivíduos ocorre pela influência dos momentos durante o dia, tais como, o estresse, medo, repouso, fome, satisfação, sede e esforço físico, que influenciam na constituição salivar (APS; MARTENS, 2005; LAMY; MAU, 2012).

Os TCO também sofrem mudanças em seu volume no decorrer do dia devido ao estímulo de várias condições, como a da mastigação (massagem gengival), influência de hormônios sexuais femininos (ovulação, gravidez, contraceptivos hormonais) relacionados a progesterona e estrógeno que aumentam a permeabilidade vascular, o ato de fumar e após terapia periodontal (processo de cicatrização) (FIORELLINI; KIM; ISHIKAWA, 2007; SILVEIRA, 2008).

Outros processos também podem mudar a natureza dos componentes do $\mathrm{FO}$, como os processos inflamatórios ou de solução de continuidade na mucosa oral. Durante essas situações, células epiteliais são liberadas e degradadas, enquanto os capilares sanguíneos têm a sua permeabilidade aumentada, resultando na liberação de componentes do soro com alto peso molecular, tais como a globulina, albumina e fibrinogênio (MARINI; CABASSI, 2002; APS; MARTENS, 2005). Essas características de instabilidade na sua composição é o principal fator que diferencia o FO do soro sanguíneo (APS; MARTENS, 2005; LAMY; MAU, 2012).

Ferri (1998), Barros et al. (1999), Madar, Straka e Baska (2002) e Mestecky et al. (2005) afirmam que as concentrações de imunoglobulinas no TCO são mais elevadas do que na saliva. Ferri (1998) argumenta em uma revisão sobre a utilização do TMO como amostra clínica no diagnóstico laboratorial do HIV que a alta viscosidade da saliva prejudica a sua coleta e que os anticorpos (anti-HIV) presentes na saliva são principalmente IgAs, enquanto os encontrados no TMO são principalmente os IgGs, classe principal de anticorpos anti-HIV.

Barros et al. (1999) pesquisaram anticorpos anti-Trypanossoma cruzi no TMO em dois grupos de indivíduos: um que apresentava a Doença de Chagas diagnosticada e outro um grupo controle, de pessoas oriundas de regiões endêmicas. O TMO foi coletado por meio de filtro de papel. O resultado apresentou uma sensibilidade de $95 \%$ e uma especificidade de $100 \%$, sendo maior do que outras pesquisas que utilizaram o FO. Os autores destacaram três pontos para justificar essa diferença: a viscosidade do FO dificulta seu processamento; Existem proteases no FO que podem degradar as imunoglobulinas; e a titulação de anticorpos específicos (IgG) no FO é menor do que no TMO e no FCG. Além disso, a quantidade de anticorpos específicos ( $\mathrm{IgG}$ ) encontrada no TMO foi quatro vezes maior do que no FO.

Segundo Hodinka, Nagashunmugam e Malamud (1998) a concentração de IgG no TMO, no entanto, é menor do que no plasma, porém maior do que o FO. Mestecky et al. (2005) afirma que o FCG quando misturado à saliva, pode chegar a uma diluição compreendida entre 1:1000 e 1:500.

\section{Considerações Finais}

De forma geral o FO tem se apresentado como um substituto em potencial do sangue e/ou soro como amostra clínica devido a facilidade e segurança do procedimento de coleta aliado ao progressivo desenvolvimento dos métodos laboratoriais. Na medicina veterinária, o FO promove o bem-estar animal, podendo auxiliar de forma mais rápida e efetiva na construção do diagnóstico definitivo das enfermidades ou nas monitórias sanitárias.

\section{Referências}

AMADO, L. A. et al. Detection of hepatitis A, B, and C virus-specific antibodies using oral fluid for epidemiological studies. Memórias do Instituto Oswaldo Cruz, Rio de Janeiro, v. 101, p. 149-155, 2006. Disponível em: <http:// goo.gl/6TbFye>. Acesso em: 13 jun. 2014.

APS, J. K. M.; MARTENS, L. C. Review: The physiology of saliva and transfer of drugs into saliva. Forensic Science International, n. 150, p. 119-131, 2005. Disponível em: $<$ http://goo.gl/1lhlxl>. Acesso em: 04 mar. 2015.

ARGENZIO, R. A. Secreções do estômago e das glândulas acessórias. In: REECE, W. O. Dukes: fisiologia dos animais domésticos. 12. ed. Rio de Janeiro: Guanabara Koogan, 2006. p. 374-386.

BADIYANI, B.; KUMAR, A.; MARU, V. P. Role of saliva in dental practice - a review. Research and Reviews: Journal of Dental Sciences, v. 1, n. 1, p. 1-6, 2013. Disponível em: <http://goo.gl/T5DUFw $>$. Acesso: 12 mar. 2015.

BAPTISTA, R. I. A. A.; BERTANI, G. R.; BARBOSA, C. N. Indicadores do bem-estar em suíno. Ciência Rural, Santa Maria, v.41, n.10, p.1823-1830, 2011. Disponível em: $<$ http://goo.gl/wB1cnN>. Acesso em: 13 jun. 2014.

\section{BAPTISTA, R. I. A. A. Avaliação comportamental e} fisiológica de suínos em baias individuais e gaiolas metabólicas. 2012. 144 f. (Mestrado em Ciência Veterinária), Departamento de Medicina Veterinária, Universidade Federal Rural de Pernambuco, Recife, 2012.

BARBOSA, C. N. et al. Aplicação da metodologia de coleta do fluido oral em suínos mestiços. Medicina Veterinária, Recife, v. 7, n. 3, p. 32-38, 2013. Disponível em: < http:// goo.gl/NvujxW>. Acesso em: 05 mar. 2015.

BARROS, M. das N. D. S.et al. Evaluation of oral mucosal transudate for immunodiagnosis of Chagas disease. Revista do Instituto de Medicina Tropical de São Paulo, São Paulo, v. 41, n. 4, p. 265-266, 1999. Disponível em: <http:// goo.gl/yw61tU>. Acesso em: 25 jan. 2015.

BELLO. I. J. G. Estúdio de marcadores de difereciación epitelial em mucosa oral contruida por ingeniería tissular. 2009. $121 \mathrm{f}$. Tese (Doutorado)- Departamento de Histologia, Faculdade de Medicina, Universidade de 
Granada, Granada, 2009.

BOACKLE, R. J.; SUDDICK, R. P. Proteínas salivares e saúde bucal. In: MENAKER, L. et al. Cáries dentárias: bases biológicas. Rio de Janeiro: Guanabara- Koogan, 1984. p.118-131.

BRILL, N.; KRASSE, B. The passage of tissue fluid into the clinically healthy gingival pocket. Acta Odontologica Scandinavica, v. 16, p. 233-245, 1958. Disponível em: $<$ http://goo.gl/upGPjs $>$. Acesso em: 24 mar. 2015.

CASTRO, M.; MOREIRA, A. C. Análise crítica do cortisol salivar na avaliação do eixo hipotálamo- hipófise-adrenal.

Arquivos Brasileiros de Endocrinologia \& Metabologia, São Paulo, v. 47, n. 4, p. 458-367, 2003. Disponível em: < http://goo.gl/TBAmgX>. Acesso em: 25 fev. 2015.

CHALLACOMBE, S. J. et al. Passage of immunoglobulins from plasma to the oral cavity in rhesus monkeys. Immunology, Bethesda, n. 35, p. 923-931, 1978. Disponível em: <http://goo.gl/8CBVn0>. Acesso em: 18 mar. 2015.

CHIAPPIN, S. et al. Saliva specimen: A new laboratory tool for diagnostic and basic investigation. Clinica Chimica Acta, n. 383, p. 30-40, 2007. Disponível em: <http://goo.gl/ DsXMdv>. Acesso em: 20 fev. 2015.

CROUCH, D. J. Oral fluid collection: The neglected variable in oral fluid testing. Forensic Science International, v.150, p.165-173, 2005.

DeLIMA, A. J.; VAN DYKE, T. E. Origin and function of the cellular components in gingival crevice fluid.

Periodontology 2000,Copenhague, v. 31, p. 55-76, 2003.

DYCE, K. M.; SACK, W. O.; WENSING, C. J. G. O Aparelho Digestivo. In: Tratado de anatomia veterinária. 2. ed. Rio de Janeiro: Guanabara Koogan, 1997. p. 79-117.

EDGAR, W. M. Saliva: its secretion, composition and functions. British Dental Journal, Londres, v. 172, n. 8, p. 305-312, 1992.

EDGAR, M. et al. Saliva and oral health. Oral health, dental tribune middle east \& Africa edition, p. 14-15, 2014. Disponível em: <http://goo.gl/lVf0a7>. Acesso em: 20 jan. 2015.

ELLENPORT, C. R. Sistema digestivo do carnívoro. In: GETTY, R. Anatomia dos animais domésticos. 5. ed. Rio de Janeiro: Guanabara Koogan, 1986. p. 1445-1464.

EMBERY, G.; WADDINGTON, R. Gingival sulcular Fluid: biomarkers of periodontal tissue activity. Advances in Dental Research, v. 8, n. 2, p. 329-336, 1994. Disponível em: <http://goo.gl/Vd2Tci>. Acesso em: 15 fev. 2015.

FELLER, L. et al. Oral mucosal immunity. Oral Medicine, v. 116, n. 5, p. 576-583, 2013. Disponível em: <http://goo. gl/87peI3>. Acesso em: 12 mar. 2015.

FERRI, R. S. Oral mucosal transudate testing for HIV-1 antibodies: a clinical update. Journal of Association of Nurses in AIDS Care, v. 9, n. 2, p. 68-72, 1998. Disponível em: <http://goo.gl/KQ3qBd>. Acesso em: 13 mar. 2015.

FIORELLINI, J. P.; KIM, D. M.; ISHIKAWA, S. O. Gengiva. In: CARRANZA F. A. et al. Carranza: Periodontia Clínica, Rio de Janeiro: Guanabara Koogan, 2007. cap. 4. p. 46-67.

GEORGE, J. R.; FITCHEN, J. Future applications of oral fluid specimen technology. The American Journal of Medicine, v.102 (Suplemento 4A), p. 21-25, 1997. Disponível em: <http://goo.gl/S02jZ4>. Acesso em: 15 mar. 2015.

GOODSON, J. M. Gingival crevice fluid flow.

Periodontology 2000, Copenhague, v. 31, p. 43-54, 2003. Disponível em: <http://goo.gl/fXlVAe>. Acesso em: 23 fev. 2015.

GRIFFITHS, G. S. Formation, collection and significance of gingival crevice fluid. Periodontology 2000, Copenhague, v. 31, p. 32-42, 2003. Disponível em: <http:// goo.gl/3T5CPJ>. Acesso em: 23 fev. 2015.

GUTIÉRREZ, A. M. et al. Use of saliva for haptoglobin and C-reactive protein quantifications in porcine respiratory and reproductive syndrome affected pigs in field conditions. Veterinary Immunology and Immunopathology, Amsterdam, v.132, p. 218-223, 2009. Disponível em: $<$ http://goo.gl/3T5CPJ>. Acesso em: 13 jun. 2014.

GUYTON, A. C.; HALL, J. E. Funções secretoras do trato alimentar. In: Tratado de fisiologia médica. 11. ed. Rio de Janeiro: Elsevier. 2006. Cap. 64, p. 791-807.

HABEL, R. E. Sistema digestivo do ruminante. In: GETTY, R. Anatomia dos animais domésticos. 5.ed.Rio de Janeiro: Guanabara Koogan, 1986. p. 807-858.

HAECKEL. R.; HANECKE, P. Application of saliva for drug monitoring. An in vivo model for transmembrane transport. European journal of clinical chemistry and clinical biochemistry, v. 34, n. 3, p. 171-91, 1996. Disponível em: <http://goo.gl/ECiJu2>. Acesso em: 25 jan. 2015.

HEIDEMANN, S. R. As bases moleculares e celulares da regulação fisiológica. In: CUNNINGHAM, J. G. Tratado de fisiologia Veterinária. 3. ed. Rio de Janeiro: Guanabara Koogan. 2004. cap.1, p. 03-29.

HELFAND, R. F. et al. Comparative detection of measlesspecific IgM in oral fluid and serum from children by an antibody-capture IgM EIA. The Journal of Infectious Diseases, Chicago, v.173, p.1470-1474, 1996. Disponível em: <http://goo.gl/hjlrBt>. Acesso em: 10 jan. 2015. 
HERDT, T. Secreções do trato digestório. In: CUNNINGHAM, J. G. Tratado de fisiologia veterinária. 3. ed. Rio de Janeiro: Guanabara Koogan. 2004. p. 254-262.

HODINKA, R. L.; NAGASHUNMUGAM, T.; MALAMUD, D. Detection of human immunodeficiency virus antibodies in oral fluids. Clinical and Diagnostic Laboratory Immunology, Washington DC, v. 5, n. 4, p. 419-426, 1998. Disponível em: <http://goo.gl/4LG9oJ>. Acesso em: 20 fev. 2015.

HUDMAN, D. B. et al. Digestive enzymes of the baby pig. Pancreatic and salivary amylase. Journal of Agricultural and Food Chemistry, Washington, v. 3, n. 9, p. 691-693, 1957.

HUMPHREY, S. P.; WILLIAMSON, R.T. A review of saliva: normal composition, flow, and function. The Journal of Prosthetic Dentistry, Saint Louis, v. 85, p.162169, 2001. Disponível em: <http://goo.gl/N2KEuZ>. Acesso em: 17 jan. 2015 .

JUNQUEIRA, L. C. U.; CARNEIRO, J. Histologia básica. 11. ed. Rio de Janeiro: Guanabara Koogan. 2012. 488 p.

KATZ, F. H.; SHANNON, I. L. Identification and significance of parotid fluid corticosteroids. Acta Endocrinology, Copenhage, v. 46, p. 393-404, 1964.

KAUFMAN, E.; LAMSTER, I. B. The diagnostic applications of saliva - a review. Oral Biology $\&$ Medicine, Alexandria, v. 13, n. 2, p. 197-212, 2002. Disponível em: $<$ http://goo.gl/aHxVEI $>$. Acesso em: 13 jun. 2014.

KITTAWORNRAT, A. et al. Kinetics of the porcine reproductive and respiratory syndrome virus (prrsv) humoral immune response in swine serum and oral fluids collected from individual boars. BMC Veterinary Research, Londres, v. 9, n. 61, p. 1-10, 2013.

LAMY, E.; MAU, M. Saliva proteomics as an emerging, non-invasive tool to study livestock physiology, nutrition and diseases. Journal of proteomics, n. 75, p. 4251-4258, 2012. Disponível em: <http://goo.gl/Q8YCvZ>. Acesso em: 10 jan. 2015.

LLENA-PUY, C. The role of saliva in maintaining oral health and as an aid to diagnosis. Medicina Oral, Patologia Oral y Cirugia Bucal, n. 11, p. 449-455, 2006. Disponível em: <http://goo.gl/qARNNE>. Acesso em: 21 jan. 2015.

MACRE, M. de S. Padronização de ensaio imunoenzimático para detecção de anticorpo IgG contra Toxoplasma gondii na saliva de escolares. 2008. 76 f. Tese (Doutorado em Ciências) - Departamento de Parasitologia, Instituto de Ciências Biomédicas, Universidade de São Paulo, São Paulo, 2008

MADAR, R.; STRAKA, S.; BASKA, T. Detection of antibodies in saliva - an effective auxiliary method in surveillance of infectious diseases. Bratislavské Lekárske Listy, Bratislava, v. 103, n. 1, p. 38-41, 2002. Disponível em: <http://goo.gl/nnF1Kz>. Acesso em: 02 fev. 2015.

MADDONIA, J. V.; BAHN, A. N.; CALANDRA, J. C. Salivary excretion of coxsackie B-1 virus in rabbits. Applied Microbiology, v. 14, n. 3, p. 394-396, 1966. Disponível em: <http://goo.gl/cuFkFT>. Acesso em: 24 mar. 2015.

MARINI, A.; CABASSI, E. La saliva: Approccio complementare nella diagnostica clinica e nella ricerca biológica. Ann. Fac. Medic. Vet. di Parma, v. 22, p. 295311, 2002. Disponível em: <http://goo.gl/kCBLN2>. Acesso em: 25 jan. 2015.

MCKIE, A.; ANDREW, V.; MAPLE, C. Novel methods for the detection of microbial antibodies in oral fluid. Lancet Infect Disease. v. 2, p. 18-24, 2002.

MESTECKY, J. et al. Mucosal immunology. 3. ed. Amsterdam: Elsevier/Academic Press, 2005. 2064 p.

MOURA, S. A. B. et al. Valor diagnóstico da saliva em doenças orais e sistêmicas: uma revisão de literatura. Pesquisa Brasileira em Odontopediatria e Clinica Integrada, João Pessoa, v. 7, n. 2, p. 187-194, 2007.

MOYES, C. D.; SCHULTE, P.M. Princípios de fisiologia animal. 2. ed. Porto Alegre: Artmed, 2010. 776 p.

NAIR, P. N. R.; SCHROEDER, H. E. Duct associated lymphoid tissue (DALT) of minor salivary gland and mucosal immunity. Immunology, Oxford, v. 57, n. 2, p. 171-180, 1986. Disponível em: <http:/goo.gl/f1v3cU>. Acesso em: 20 fev. 2015.

NAVAZESH, M. Methods for collecting saliva. Annals of the New York Academy of Sciences, Nova Iorque, n. 694, p. 72-77. 1993. Disponível em: <http://goo.gl/10hLF7>. Acesso em: 15 jan. 2015.

NGOUNOU WETIE, A. G. et al. A pilot proteomic of salivary biomarkers in autism a spectrum disorder. Autism Research, Hoboken, p. 1-13, 2015. Disponível em: <http:// goo.gl/y4JbnW>. Acesso em: 05 mar. 2015.

PANDESHWAR, P.; DAS, R. Role of oral fluids in DNA investigations. Journal of Forensic and Legal Medicine, v. 22, p. 45-50, 2014.

PARROTT, R. F.; MISSON, B. H.; BALDWIN, B. A. Salivary cortisol in pigs following adrenocorticotrophic hormone stimulation: comparison with plasma levels. The British Veterinary Journal, Londres, v. 145, n. 4, p. 362366, 1989.

PARROTT, R. F.; MISSON, B. H. Changes in pig salivary cortisol in response to transport simulation, food and water deprivation, and mixing. The British Veterinary Journal, Londres, v. 145, n. 6, p. 501-505, 1989. 
PFAFFE, T. et al. Diagnostic potential of saliva: Current state and future applications. Clinical Chemistry, v. 57, n. 5, p. 675-687, 2011. Disponível em: <http://goo.gl/ f0h9A1>. Acesso em: 05 fev. 2015.

PRICKETT, J. R.; ZIMMERMAN, J. J. The development of oral fluid-based diagnostics and application in veterinary medicine. Animal Health Research Reviews, Wallingford, v. 11, n. 2, p. 207-216, 2010. Disponível em: <http://goo.gl/ Zsi6OR>. Acesso em: 13 jun. 2014.

RATCLIFF, P. A. Permeability of healthy gingival epithelium by microscopically observable particles. Journal Periodontol, v. 37, p. 28-29, 1966.

ROUX, M. N.; NOCARD, M. At what moment does the virus of rabies appear in the saliva of rabid animals? Journal of Comparative Pathology and Therapeutics. v. 3, p. 128-134, 1890. Disponível em: <http://goo.gl/ krXSXH>. Acesso em: 20 fev. 2015.

SANTOS, P. P. A. et al. Saliva: métodos atuais para coleta e obtenção da amostra. Revista da Faculdade de Odontologia de Porto Alegre, Porto Alegre, v. 48, n. 1/3, p. 95-98, 2007. Disponível em: <file:///C:/Users/ Usu\%C3\%A1rio/Downloads/7516-24714-1-PB.pdf $>$. Acesso em: 05 mar. 2015.

SJAASTAD, O. V.; SAND, O.; HOVE, K. Physiology of domestic animals. 2. ed. Oslo: Scandinavian Veterinary Press, 2010. 804 p.

SHACKLEFORD, J. M.; WILBORN, W. H. Structural and histochemical diversity in mammalian salivary glands. The Alabama Journal Medical Sciences, v. 5, p. 180-203, 1968.

SHAFIQ, N.; MALHOTRA, S. Use of antibiotics in community-acquired pneumonia. In: JINDAL, S. K.; GULERIA, R. World clinics pulmonary \& critical care medicine: pneumonias. Jaypee: Daryaganj, 2012. p. 95-116.

SILVA, C. O.; SALLUM; A. W.; NOGUEIRA FILHO; G. R. Contribuição dos biomarcadores do fluido gengival no diagnóstico periodontal. Periodontia, v. 4, n. 4, p. 44-47, 2004. Disponível em: <http://goo.gl/jlkWZ3>. Acesso em: 15 jan. 2015.

SILVEIRA, L. de B. Avaliação das alterações do Fluido Crevicular Gengival drenado de tecidos gengivais clinicamente normais submetidos à radiação laser em baixa intensidade (estudo em Anima Nóbile). 2008. 141 f. Tese (Doutorado em Engenharia Mecânica) - Escola de Engenharia, Universidade Federal de Minas Gerais, Belo Horizonte, 2008.

SISSON, S. S. Sistema digestivo do equino. In: GETTY, R. Anatomia dos animais domésticos. 5. ed. Rio de Janeiro: Guanabara Koogan, 1986a. p. 424-465.

SISSON, S. S. Sistema digestivo do suíno. In: GETTY, R.
Anatomia dos animais domésticos. 5. ed. Rio de Janeiro: Guanabara Koogan, 1986b. p. 1188-1202.

SOLER, L.; GUTIÉRREZ, A.; CÉRON, J. J. Serum amyloid A measurements in saliva and serum in growing pigs affected by porcine respiratory and reproductive syndrome in field conditions. Research in Veterinary Science, v. 93, n. 3, p. 1266-1270, 2012.

SQUIER, C. A.; KREMER, M. J. Biology of oral mucosa and esophagus. Journal of The National Cancer Institute Monographs, Oxford, n. 29, p. 7-15, 2001. Disponível em: $<$ http://goo.gl/YABUkB>. Acesso em: 10 jan. 2015.

SUGIMOTO, M. et al. Capillary electrophores is mass spectrometry-based saliva metabolomics identified oral, breast and pancreatic cancer-specific profiles.

Metabolomics, Nova Iorque, v. 6, n. 1, p. 78-95, 2010. Disponível em: <http://goo.gl/1KVBc1>. Acesso em: 13 jun. 2014.

TENOVUO, J.; LAGERLÖ, F.; Saliva. In: THYLSTRUP, A.; FEJERSKOV, O. Cariologia clínica. 2. ed. São Paulo: Santos, 1995, p. 17-43.

TIZARD, I. R. Anticorpos: formas solúveis de RCB. In: Imunologia veterinária: uma introdução. 5 . ed. São Paulo, Roca. 1998. p. 160-171.

UITTO, V. J. Gingival crevice fluid - an introduction. Periodontology 2000, Copenhagen, v. 31, p. 9-11, 2003. Disponível em: < http://goo.gl/oq5o8l>. Acesso em: 15 jan. 2015.

VINNING, R. F. et al. Salivary cortisol: a better measure of adrenal cortical function than serum cortisol. Annals of Clinical Biochemistry, Londres, v. 20, n. 6, p. 329-335, 1983.

WARRENER, L.; SAMUEL, D. Evaluation of a commercial assay for the detection of mumps specific IgM antibodies in oral fluid and serum specimens. Journal of Clinical Virology, Amsterdam, v. 35, n. 2, p. 130-134, 2006. Disponível em: <http://goo.gl/E68oaX>. Acesso em: 13 jun. 2014.

WIGGS, R. B.; LOBPRISE, H. B. Oral anatomy and physiology. In: . Veterinary dentristy, principles and practice. Philadelphia, PA: Lippincott-Raven Publishers, 1997. p. 55-86. 